\title{
A Combined Climate Extremes Index for the Australian Region
}

\author{
Ailie J. E. GALlant AND DAVID J. KAROLY \\ School of Earth Sciences, University of Melbourne, Melbourne, Victoria, Australia
}

(Manuscript received 19 April 2010, in final form 17 August 2010)

\begin{abstract}
Changes in the area of Australia experiencing concurrent temperature and rainfall extremes are investigated through the use of two combined indices. The indices describe variations between the fraction of land area experiencing extreme cold and dry or hot and wet conditions. There is a high level of agreement between the variations and trends of the indices from 1957 to 2008 when computed using (i) a spatially complete gridded dataset without rigorous quality control checks and (ii) spatially incomplete high-quality station datasets with rigorous quality control checks. Australian extremes are examined starting from 1911, which is the first time a broad-scale assessment of Australian temperature extremes has been performed prior to 1957. Over the whole country, the results show an increase in the extent of hot and wet extremes and a decrease in the extent of cold and dry extremes annually and during all seasons from 1911 to 2008 at a rate of between $1 \%$ and $2 \%$ decade ${ }^{-1}$. These trends mostly stem from changes in tropical regions during summer and spring. There are relationships between the extent of extreme maximum temperatures, precipitation, and soil moisture on interannual and decadal time scales that are similar to the relationships exhibited by variations of the means. However, the trends from 1911 to 2008 and from 1957 to 2008 are not consistent with these relationships, providing evidence that the processes causing the interannual variations and those causing the longer-term trends are different.
\end{abstract}

\section{Introduction}

The ongoing analysis of climate extremes is a priority for global and regional climate monitoring efforts, primarily because of the link between extreme conditions and socioeconomic impacts (Easterling et al. 2000). Changes in the frequency and severity of some extreme events during the twentieth and early twenty-first century have been recorded globally (Frich et al. 2002; Alexander et al. 2006) and throughout Europe (Klein Tank and Können 2003), North America (Karl et al. 1996; Vincent and Mekis 2006), South America (Vincent et al. 2005; Haylock et al. 2006), Asia (Manton et al. 2001; Zhai et al. 2005; You et al. 2008), and Oceania (Plummer et al. 1999; Alexander et al. 2007). These changes have included increases in the occurrence of hot extremes and decreases in the occurrence of cold extremes of minimum and maximum temperature during the second-half of the twentieth century for the majority of global land area (Frich et al. 2002; Alexander et al. 2006). Reported

Corresponding author address: Dr. Ailie Gallant, School of Earth Sciences, University of Melbourne, Melbourne, VIC, 3010, Australia. E-mail: agallant@unimelb.edu.au changes in extreme precipitation are regionally dependent. However, there has been a global trend toward increases in extreme daily precipitation during the second-half of the twentieth century and into the twentyfirst century (Alexander et al. 2006).

Tools for monitoring changes in extremes have been developed primarily through the use of indices (Frich et al. 2002). These indicators are useful for comprehensively assessing changes in a range of extremes at single or multiple locations. However, when trying to form a simple overview of how extremes are changing in a broad region, the large amount of information that multiple indicators provide can make communication with nonscientists difficult. To combat this problem, Karl et al. (1996) developed a combined index known as the Climate Extremes Index (CEI) to act as a communication tool that provides an initial indication of how combined extremes are changing over time. The CEI determines the areal extent of climate extremes for a specified region during a given year and is achieved by averaging several components, each identifying the fraction of an area experiencing a specific type of extreme associated with temperature or precipitation (Karl et al. 1996; Gleason et al. 2008). For this study, the CEI has been 
modified to provide additional information on the direction of changes in climate extremes for a region, for example, toward hotter and wetter extremes. Changes in daily temperature extremes are also included following Burkholder (2007), as Karl et al. (1996) and Gleason et al. (2008) examined monthly or longer time scales only. However, it is the daily events that often yield the greatest socioeconomic impacts (Fouillet et al. 2006).

Here, the modified CEI is calculated for Australia. This provides a practical example to demonstrate the usefulness of the CEI in regional applications and also contributes to the body of work describing regional changes in climate extremes around the globe. In Australia, widespread changes in extreme temperatures and some regional changes in extreme precipitation have been detected. Consistent with the global picture, increases in hot daily minimum and maximum temperature extremes were observed during the second-half of the twentieth century across most of the country, with the exception of some isolated pockets on the southeast coast, in the southwest, and the northwest (Collins et al. 2000; Alexander et al. 2007). An Australia-wide examination of extreme temperatures prior to the late 1950s has not previously been possible because of the lack of digitized, reliable data before this time (Trewin 2001). The trends in extreme daily and monthly precipitation in Australia are regionally and seasonally dependent. Increases in extreme rainfall from 1910 to the early 2000s have been detected in northwest Australia during summer. At the same time, there were decreases in extreme rainfall during winter in southwest Western Australia and during autumn in southeast Australia (Alexander et al. 2007; Gallant et al. 2007). The interannual variations in mean temperature and rainfall are closely associated across much of Australia, making the joint examination of changes in temperature and rainfall extremes particularly interesting. Utilizing the modified version of the CEI, and a newly available Australia-wide temperature and rainfall dataset, variations and trends in Australian climate extremes are analyzed from 1911 to 2008 .

\section{The Climate Extremes Index}

The CEI components defined by Karl et al. (1996) calculate the fraction of the area of a region experiencing extreme minimum and maximum temperatures, drought/moisture surplus, daily precipitation, and wet/ dry days calculated on monthly or longer time scales. The CEI components identify extremes in both tails of the distribution, that is, hot and cold temperature extremes and wet and dry extremes. These upper and lower extremes were added to generate each component.
However, adding the extremes only indicates whether an extreme is occurring; it does not provide any information about the type of extreme being experienced. Subtraction of the lower extreme from the upper (or vice versa) provides this directional information (Burkholder 2007) and represents the component as an anomaly, which is used to examine departures from the normal occurrence of extremes.

There are potential limitations in subtracting upper and lower extremes due to a cancellation if extremes in both tails of a distribution are changing in tandem. In Australia, changes in local extremes have been more closely associated with shifts in distributions rather than changes in variance (Alexander et al. 2007), and so the simultaneous change of upper and lower extremes at a particular location is unlikely. A cancellation of a component may also occur if there are opposing changes in extremes across a region, that is, a region is simultaneously experiencing more hot and cold extremes. Though the user may wish to know which type of extreme is dominating the region, examining smaller regions should reduce such a problem.

Here, the directional aspect was included for each component using subtraction as it introduces the flexibility to infer variations between broad extreme climate types from the CEI. For example, the CEI could be used to describe variations in a climate with more extreme hot/dry, cold/wet, hot/wet, or cold/dry conditions. This is particularly useful for Australia, where interannual variations in temperature and rainfall are often linked.

The components used for this study are described in Table 1. Each component represents changes in the fraction of the area of a region experiencing extreme minimum and maximum temperatures, drought or moisture surplus, heavy daily rainfall, and wet and dry days. Two versions of the CEI are calculated that, following modifications by Burkholder (2007), utilize the subtraction method. The first is the modified CEI (mCEI), and the second is the daily, modified CEI (dmCEI). The difference between the mCEI and dmCEI is that they calculate temperature extremes on the monthly and daily time scale, respectively. Specifically, the temperature components in the mCEI compute fractions of area where the mean temperature exceeds an extreme threshold, whereas the dmCEI computes fractions of area where the proportion of daily temperature extremes exceed an extreme threshold. Before combination, component 4 was multiplied by two to make the variance similar to the other components, which effectively have doubled variance from the combination of upper and lower extremes. Taking a simple average of all components generates the mCEI and dmCEI time series. The mCEI and dmCEI should be viewed as 
TABLE 1. Descriptions of the mCEI, dmCEI, and their components. The indices return variations in the percentage area of a region experiencing a climate extreme. All percentile thresholds are determined from data over the entire period of the record.

\begin{tabular}{|c|c|c|c|}
\hline Component No. & Component name & $\mathrm{mCEI}$ & $\mathrm{dmCEI}$ \\
\hline 1 & Max temperature & $\begin{array}{l}\text { The percentage area where the avg max } \\
\text { temperature is above the } 90 \text { th percentile, } \\
\text { minus the percentage where the avg max } \\
\text { temperature is below the } 10 \text { th percentile. }\end{array}$ & $\begin{array}{l}\text { The percentage area where the proportion } \\
\text { of hot }{ }^{\mathrm{a}} \text { days is above the 90th percentile, } \\
\text { minus the percentage area where the } \\
\text { proportion of cold }{ }^{\mathrm{b}} \text { days is above the } \\
\text { 90th percentile }\end{array}$ \\
\hline 2 & Min temperature & $\begin{array}{l}\text { The percentage area where the avg min } \\
\text { temperature is above the 90th percentile, } \\
\text { minus the percentage where the avg min } \\
\text { temperature is below the 10th percentile. }\end{array}$ & $\begin{array}{l}\text { The percentage area where the proportion } \\
\text { of hot }{ }^{\mathrm{a}} \text { nights is above the 90th percentile, } \\
\text { minus the percentage area where the } \\
\text { proportion of cold }{ }^{\mathrm{b}} \text { nights is above } \\
\text { the } 90 \text { th percentile. }\end{array}$ \\
\hline 3 & Drought/moisture surplus & $\begin{array}{l}\text { The percentage area where the avg soil } \\
\text { moisture content is above the 90th } \\
\text { percentile, minus the percentage area } \\
\text { where the avg soil moisture content is } \\
\text { below the } 10 \text { th percentile }\end{array}$ & As in $\mathrm{mCEI}$. \\
\hline 4 & Heavy precipitation & $\begin{array}{l}\text { The percentage area where the proportion } \\
\text { of heavy rain days }{ }^{\mathrm{c}, \mathrm{d}} \text { is above the } 90 \text { th } \\
\text { percentile. }\end{array}$ & As in $\mathrm{mCEI}$. \\
\hline 5 & Wet/dry days & $\begin{array}{l}\text { The percentage area where the No. of } \\
\text { rain days }{ }^{c} \text { is above the } 90 \text { th percentile, } \\
\text { minus the percentage area where the } \\
\text { No. of dry days }{ }^{\mathrm{c}} \text { is above the } 90 \text { th } \\
\text { percentile }\end{array}$ & As in $\mathrm{mCEI}$. \\
\hline
\end{tabular}

\footnotetext{
${ }^{\text {a }}$ Hot days (nights) are defined as days (nights) where the daily max (min) temperature exceeds the 90th percentile.

${ }^{\mathrm{b}}$ Cold days (nights) are defined as days (nights) where the daily max (min) temperature falls below the 10th percentile.

${ }^{\mathrm{c}}$ A rain day (dry day) is defined as a day with rainfall greater (less) than $1.0 \mathrm{~mm}$.

${ }^{\mathrm{d}}$ A heavy rain day is defined as a day where the rainfall tot exceeds the 90 th percentile.
}

complementary to the CEI of Karl et al. (1996), not as an alternative to it.

\section{Data}

A dense and evenly spaced data network with longterm, reliable data is required for assessing changes in spatial variations of Australian climate extremes. Highquality data are necessary as spurious data often take the form of outliers. These outliers may be accidentally included as an extreme and bias the analysis of extreme events. To ensure the data extent and quality requirements were met, two datasets were utilized.

The first is a gridded dataset that has spatial completeness across the continent and a record extending from 1911 to 2008. The product was generated by the Australian Bureau of Meteorology by interpolating monthly and daily maximum and minimum temperature and rainfall station data on a $5-\mathrm{km}$ grid (Jones et al. 2007). The interpolated surfaces were generated using between 2967 and 7278 rainfall stations and between 61 and 757 temperature stations (Fig. 1a). The data available for interpolation onto the gridded surface rapidly increased in the late 1950s and early 1960s, though at all times the number of available rainfall stations is an order of magnitude larger than the number of temperature stations. The majority of these stations are located in the south and east of the country with some data gaps in northwest and central Australia. Prior to the 1970s, fewer stations were available for constructing the gridded data (Fig. 1a), leading to large data gaps in some areas. When this occurred, the grid points near these gaps reverted to climatology. Three climatologies were used based on one of the three periods of 1911-40,194170, and 1971-2000. The climatology chosen is that which matches the date when the data gap exists. (W. Wang 2010, personal communication). The grid points containing climatologies for extended periods (years) have been identified by the data providers and are masked in subsequent analyses (gray shading in Figs. 1b and 1c). For this study, the data were subsampled onto a $25-\mathrm{km}$ grid to increase computational efficiency.

The second is a set of high-quality daily temperature and rainfall data stations, provided by the Australian Bureau of Meteorology, that have been subjected to thorough quality control procedures including examination of metadata and detection and correction of artificial inhomogeneities (Lavery et al. 1992; Trewin 2001). The lengths of each record are station dependent. However, most temperature stations have reliable data from 


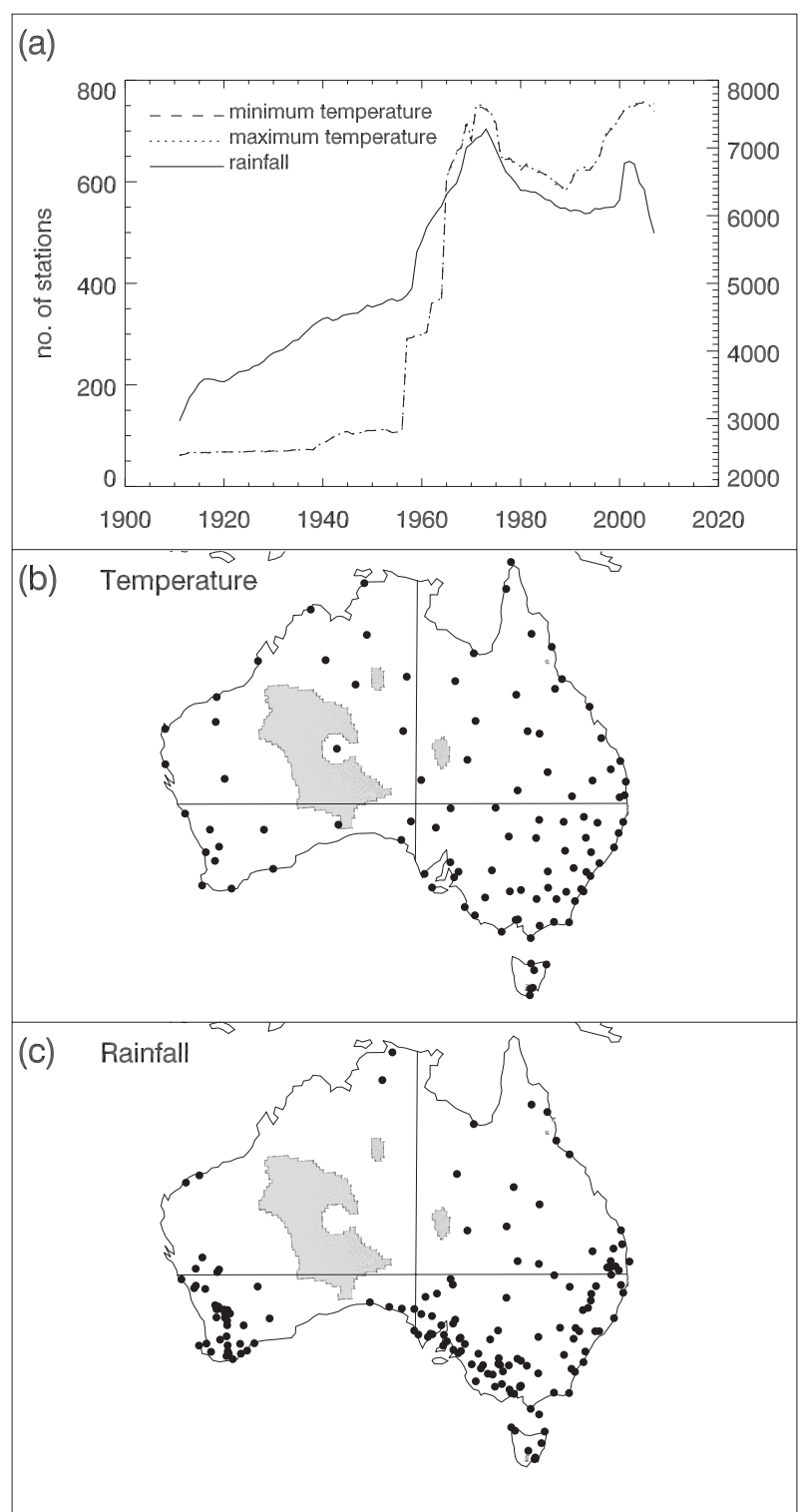

FIG. 1. (a) The average number of stations used each year to generate the $0.05^{\circ} \times 0.05^{\circ}$ daily and monthly temperature and rainfall surfaces from 1911 to 2008, (b) the high-quality daily minimum and maximum temperature records, and (c) the highquality daily rainfall records are shown. The gray areas show masked portions of the gridded dataset where data were unreliable. The solid lines delineate the four subregions.

1957, and so the high-quality records were analyzed from 1957 to 2008 only. The high-quality temperature dataset, developed by Trewin (2001), contains 103 stations across Australia (Fig. 1b). However, one station, Butler's Gorge in Tasmania, was removed because of incorrect data recording from 2006. Trewin (2001) first assessed station data for outliers using simple statistical techniques. Any questionable data were cross validated against metadata for possible artificial causes. Following this, artificial inhomogeneities in the station time series were identified and corrected on the daily time scale at the percentile level. The high-quality daily rainfall dataset was developed by Lavery et al. (1992). Daily rainfall data from approximately 6600 rainfall stations were tested for spurious trends and inhomogeneities using examination of metadata and statistical tests. Stations were only included in the high-quality dataset if none of these were identified. This resulted in a final high-quality subset of 191 stations, which has since been reduced to 152 stations by the Australian Bureau of Meteorology following several station closures (Fig. 1c).

All CEI components were calculated from gridded surfaces and high-quality station data except for component 3 (Table 1), which used gridded data only. Highquality soil moisture observations are not available in Australia. Therefore, component 3 utilized soil moisture reanalysis data from the Australian Water Availability Project (Raupach et al. 2009) to examine extreme dry and wet conditions.

\section{Methods}

The mCEI, dmCEI, and their components were computed for Australia from 1911 to 2008 using gridded data and from 1957 to 2008 using both gridded and highquality datasets. Though the sign of the trends in the frequency of local temperature extremes has been reasonably consistent across the country (Alexander et al. 2007), there have been regional trends of opposite sign in extreme precipitation and drought conditions (Alexander et al. 2007; Gallant et al. 2007). Therefore, the CEI and its components were also computed for four subregions: northeast, southeast, southwest, and northwest (Figs. 1b and $1 \mathrm{c}$ ). The mCEI and dmCEI are calculated for Australia and the four subregions annually and for the traditional austral seasons of summer [December-February (DJF)], autumn [March-May (MAM)], winter (JuneJuly (JJA)], and spring [September-November (SON)].

For all components, the upper extremes were represented as events above the 90th percentile and the lower extremes as below the 10th percentile. This equates to the hottest/coldest or wettest/driest $10 \%$ of years. The percentile thresholds were calculated relative to the entire record as this reduces the potential for the components to saturate (i.e., reach their maximum or minimum bounds), which is a possibility when using indices that are expressed as a percentage. Components 1 and 2 (Table 1) were calculated using monthly and daily minimum and maximum temperature anomalies for the mCEI and dmCEI, respectively. The monthly anomalies were computed by removing the climatological monthly mean. Daily anomalies were generated by removing 
a climatological 31-day mean, which was calculated using data 15 days on either side of the day in question. The anomalies were calculated relative to 1911-2008 and 1957-2008 for the gridded surfaces and relative to 1957-2008 only for the high-quality stations. The heavy rain days component was determined from rain days only, where rain days were defined as days with at least $1.0 \mathrm{~mm}$ of rain. The same definition was applied to define a wet day for component 5. For consistency with other components, component 4 was redefined as an anomaly after its calculation (i.e., the long-term mean was removed) so it varied about a long-term value of zero.

Each point on the gridded data surface represents a $0.25^{\circ} \times 0.25^{\circ}$ box, from which the surface area was calculated from the valid grid points only (i.e., the shaded grid boxes in Figs. 1b,c were not included). For the highquality stations, the area represented by each station was determined using Thiessen polygons, where the nodes of the polygons are points that are equidistant between proximate stations (Thiessen 1911). In some cases, the weighting given to individual stations is high. For example, only eight stations are available in northwest Australia for daily rainfall (Fig. 1c). These eight stations represent a considerable area compared to stations in the southeast where data are plentiful. As such, the results in data-sparse regions should be judged relative to the amount of data that was available.

Linear trends were calculated from the time series of the mCEI, dmCEI, and their components for Australia and the four subregions using least squares linear regression. The trends were computed from 1957 to 2008 for both datasets and from 1911 to 2008 using the gridded data only. The Mann-Kendall test was used to determine the statistical significance of tendencies in the time series using a significance level of $5 \%$. The similarities between the gridded and high-quality datasets and between components are calculated using correlations and root-mean-square error (RMSE). The statistical significance for all correlations was determined using a two-sided Student's $t$ test with a significance level set at $5 \%$.

\section{Results}

\section{a. Australian $m C E I$ and dmCEI components}

The interannual and 5-yr variations of the annual Australian mCEI and dmCEI components are shown in Figs. 2 and 3. Smoothing the data over 5 yr illustrates lower-frequency variations while keeping data loss at the endpoints of the time series to a minimum. For the temperature-based components (Fig. 2), a positive value indicates a larger fraction of area experiencing
Australia - annual
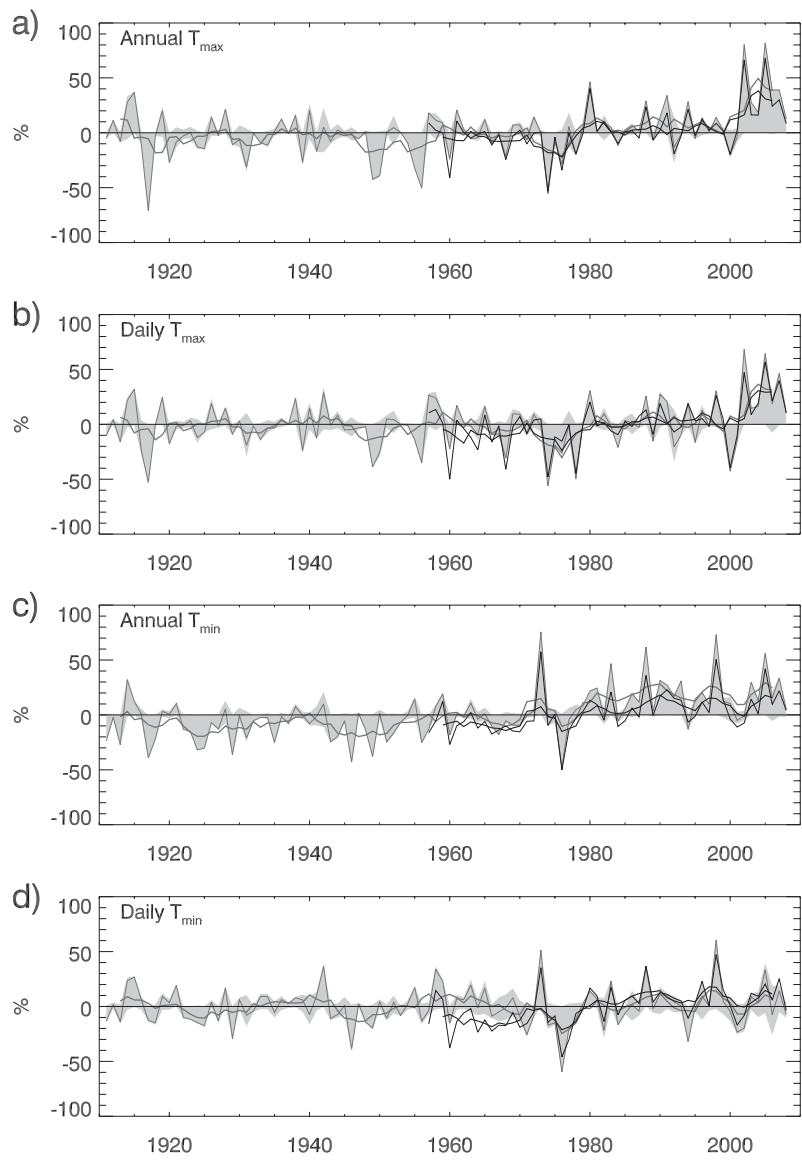

FIG. 2. The time series show interannual (solid line) and 5-yr (thick solid line) variations in the annual mCEI and dmCEI temperature-based components for Australia. The time series describe variations in the percentage area of the Australian landmass experiencing the following: (a) extreme annual maximum temperatures, (b) extreme proportions of daily maximum temperatures, (c) extreme annual minimum temperatures, and (d) extreme proportions of daily minimum temperatures. Positive values indicate extreme hot conditions and negative values extreme cold conditions. The shaded light-gray areas represent the upper and lower extremes comprising each component. The time series generated from the gridded dataset from 1911 to 2008 are shown in dark gray, and those generated from the high-quality dataset from 1957 to 2008 are shown in black.

hot extremes and a negative value a larger extent of cold extremes. For the soil moisture- and rainfall-based components (Fig. 3), a positive value indicates a greater fraction of area experiencing extreme wet conditions and a negative value a greater extent of extreme dry conditions.

If the two tails of a variable show concurrent large anomalies then the subtraction method would cause a cancellation, which underestimates the magnitude of the spatial changes in extremes. However, Figs. 2 and 3 show that there were very few instances when there was 


\section{Australia - annual}
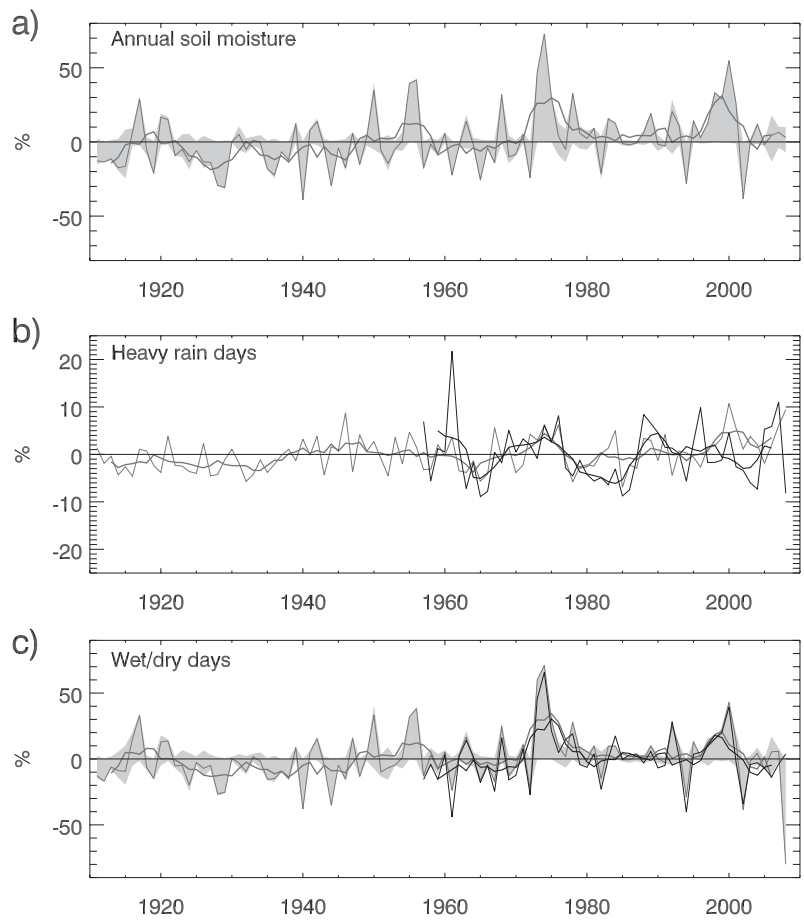

FIG. 3. The time series show interannual (solid line) and 5-yr (thick solid line) variations in the annual mCEI and dmCEI soil moisture- and precipitation-based components for Australia. The time series describe variations in the percentage area of the Australian landmass experiencing the following: (a) extreme drought or moisture surplus conditions, (b) extreme proportions of annual rainfall from heavy rain days, and (c) an extreme number of wet or dry days. Positive values indicate extreme wet conditions and negative values extreme dry conditions. The shaded light-gray areas represent the upper and lower extremes comprising each component. The time series generated from the gridded dataset from 1911 to 2008 are shown in dark gray, and those generated from the high-quality dataset from 1957 to 2008 are shown in black.

a cancellation of terms in the mCEI and dmCEI components for the Australian region (e.g., from approximately 1940 to 1945 in Fig. 2a). Deviations in a component of more than approximately $10 \%$ were very rarely accompanied by a similar or larger anomaly of the opposite sign, indicating that extremes at the opposite ends of the spectrum do not tend to occur concurrently across the country. Therefore, the subtraction method was applied to all mCEI and dmCEI components, which meant information on the type of extreme (e.g., hot, cold, wet, or dry) was included.

The standard deviations of each component were computed to describe the average magnitudes of the variations in the extent of extreme conditions. All time series were detrended, as a strong trend in a time series will artificially inflate its standard deviation. The largest
Australia - annual

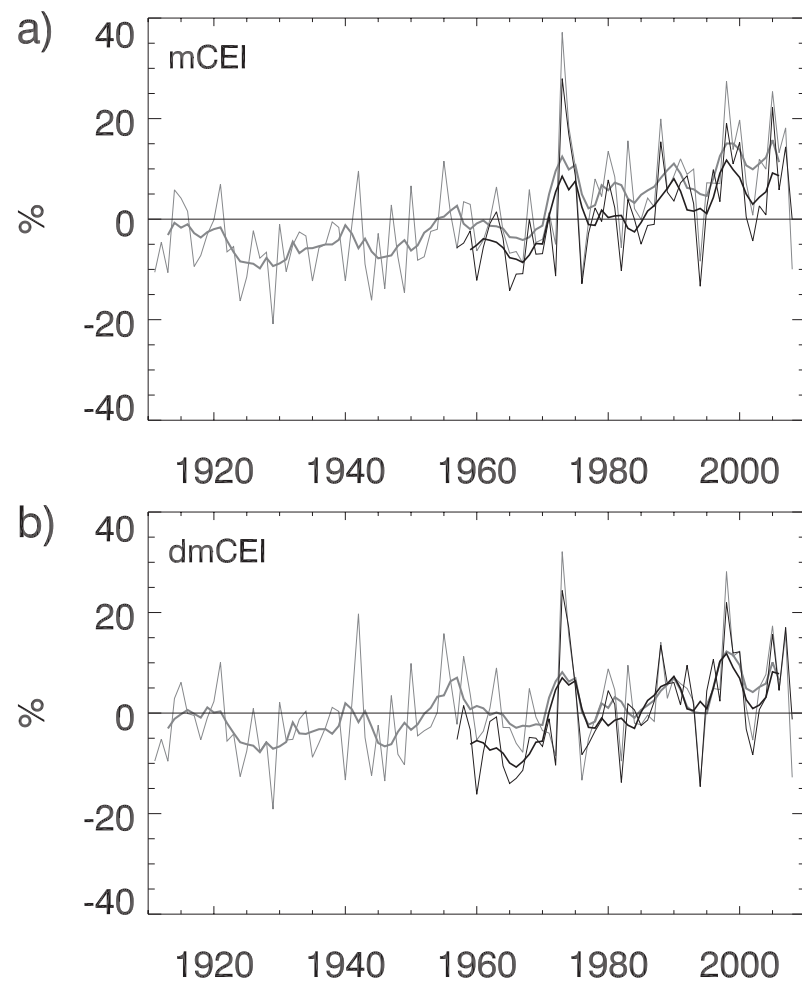

FIG. 4. The time series show interannual (solid line) and 5-yr (thick solid line) variations in the annual Australian (a) mCEI and (b) dmCEI. Positive values indicate extreme hot and wet conditions and negative values extreme cold and dry conditions. The time series generated from the gridded dataset from 1911 to 2008 are shown in dark gray, and those generated from the high-quality dataset from 1957 to 2008 are shown in black.

interannual variations were in the temperature components, which had standard deviations of approximately $20 \%$. The fraction of the country experiencing heavy daily rainfall had the smallest standard deviation of $6 \%$. The larger variance in the other components is because they combine two elements (an upper and lower extreme), which effectively doubles the variance. To make the variance of all components comparable, the heavy daily rainfall component was doubled before it was included in the mCEI and dmCEI. However, even after a doubling of the standard deviation, the variations of the heavy daily rainfall component were less than those of other components. The drought/moisture surplus component and wet/dry days component had similar standard deviations, with average anomalies of $18 \%$ and $17 \%$, respectively.

Prior to approximately 1980 , the country experienced a greater extent of colder minimum and maximum temperature extremes compared to hotter extremes. After 1980, the hot extremes dominated the land area 


\section{Southeast - MAM}

a)

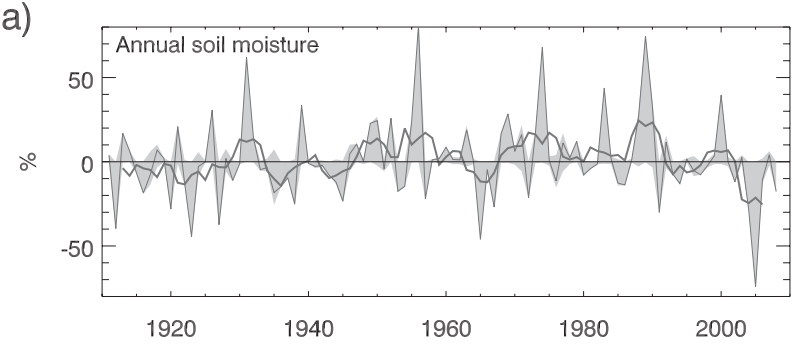

b)

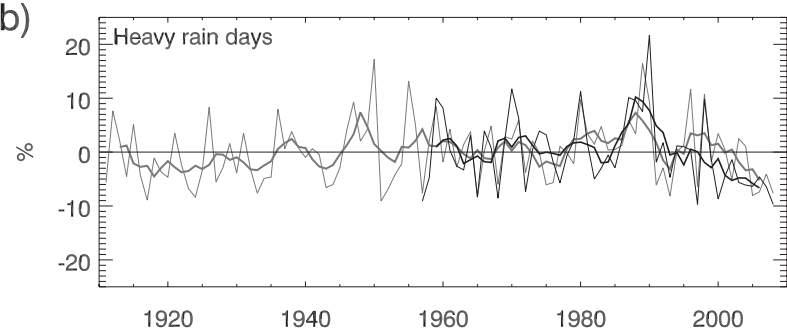

c)

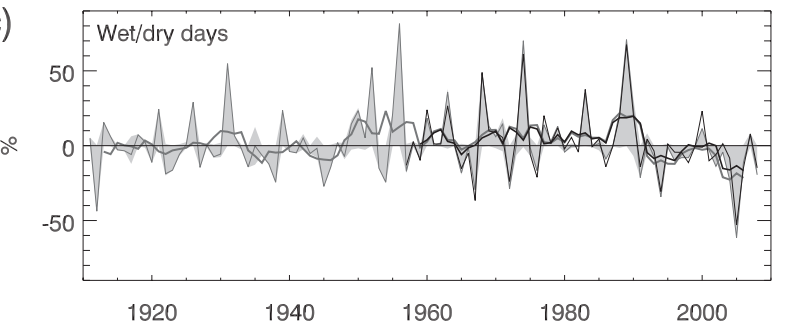

FIG. 5. The time series show interannual (solid line) and 5-yr (thick solid line) variations in the MAM precipitation- and soil moisture-based components for the southeast. The time series describe variations in the percentage area of the southeast experiencing the following: (a) extreme drought or moisture surplus conditions, (b) extreme proportions of annual rainfall from heavy rain days, and (c) an extreme number of wet or dry days. Positive values indicate extreme wet conditions and negative values extreme dry conditions. The shaded light-gray areas represent the upper and lower extremes comprising each component. The time series generated from the gridded dataset from 1911 to 2008 are shown in dark gray, and those generated from the high-quality dataset from 1957 to 2008 are shown in black.

(Figs. 2a-2d). The shift was most evident in extreme annual minimum temperatures, where prior to 1980 there was a larger extent of cold extremes compared to hot extremes during $70 \%$ of years (Fig. 2c). However, post-1980 only $7 \%$ of years had such anomalies. Large anomalies of hot annual and daily maximum temperature extremes have dominated the post-2000 record (Fig. 4). During 2002 and 2005, over $80 \%$ and $65 \%$ of the continent experienced extreme hot annual and daily maximum temperatures, respectively. Though these anomalies can be partially attributed to the occurrence of El Niños during these years, the fraction of Australia that experienced such conditions was at least $30 \%$ larger than the anomalies during all previous El Niño

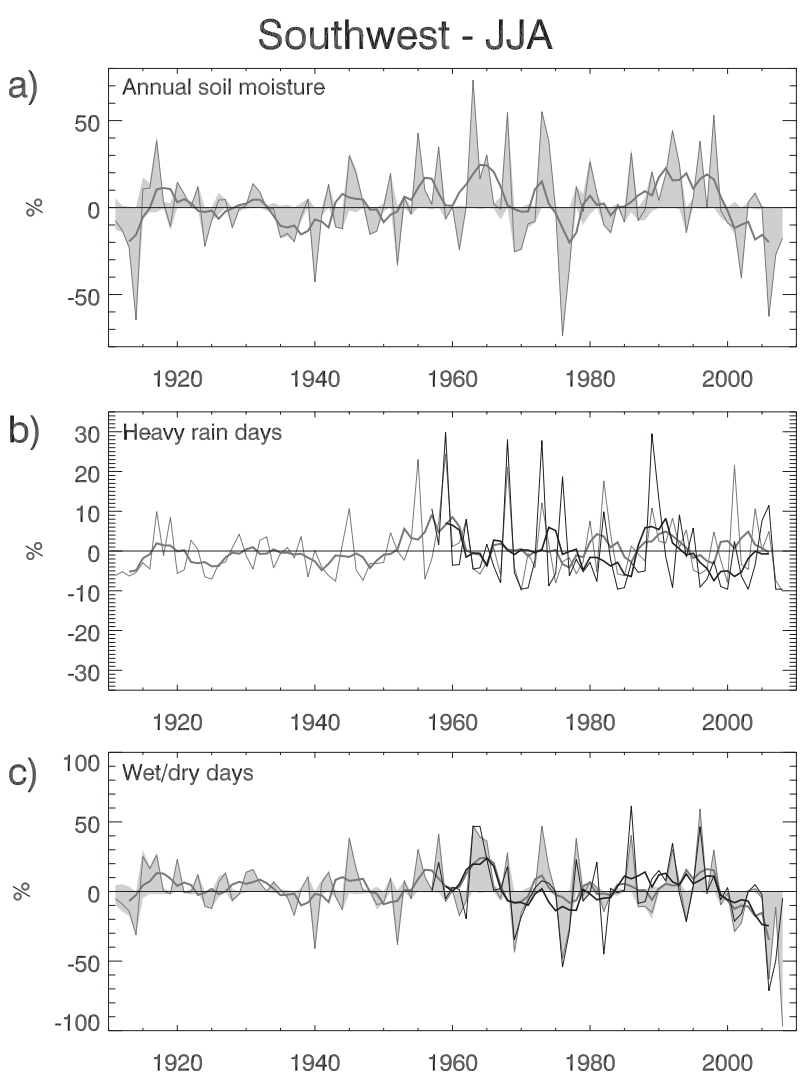

FIG. 6. The time series show interannual (solid line) and 5-yr (thick solid line) variations in the JJA precipitation- and soil moisture-based components for the southwest. The time series describe variations in the percentage area of the southwest experiencing the following: (a) extreme drought or moisture surplus conditions, (b) extreme proportions of annual rainfall from heavy rain days, and (c) an extreme number of wet or dry days. Positive values indicate extreme wet conditions and negative values extreme dry conditions. The shaded light gray areas represent the upper and lower extremes comprising each component. The time series generated from the gridded dataset from 1911 to 2008 are shown in dark gray, and those generated from the high-quality dataset from 1957 to 2008 are shown in black.

events, including strong events such as 1982/83 and $1997 / 98$.

The changes in temperature extremes reflect longterm trends toward more of the country experiencing hotter minimum and maximum temperature extremes from 1911 to 2008, which are consistent with increases in mean temperature across the country (Della-Marta et al. 2004). There were strong correlations between annual mean maximum (minimum) temperatures and the annual mCEI maximum (minimum) temperature component of $0.96(0.97)$. The association between the mean maximum temperature and the extent of the daily extremes of maximum temperature is similar (0.92) but weaker for daily minimum temperatures (0.78). Extreme daily minimum temperatures are more likely to be driven 
TABLE 2. The linear trends in the annual mCEI and dmCEI and their components for the Australian region as calculated from the gridded and high-quality datasets. The gridded trends have been computed using data from 1911 to 2008 and from 1957 to 2008. The high-quality trends have been computed using data from 1957 to 2008 only. All trends are expressed as a percentage change in the component per decade. The trends highlighted in bold are significant at the $5 \%$ level according to the Mann-Kendall test.

\begin{tabular}{lccc}
\hline \hline Component & $\begin{array}{c}\text { Gridded } \\
(1911-2008)\end{array}$ & $\begin{array}{c}\text { Gridded } \\
(1957-2008)\end{array}$ & $\begin{array}{c}\text { High quality } \\
(1957-2008)\end{array}$ \\
\hline 1 & $\mathbf{2 . 5 7}$ & $\mathbf{5 . 5 6}$ & $\mathbf{6 . 1 4}$ \\
1 (daily) & 1.42 & 3.64 & $\mathbf{6 . 1 0}$ \\
2 & $\mathbf{3 . 9 4}$ & $\mathbf{5 . 9 7}$ & $\mathbf{5 . 2 7}$ \\
2 (daily) & 0.35 & 0.27 & $\mathbf{5 . 5 8}$ \\
3 & $\mathbf{2 . 2 0}$ & $\mathbf{2 . 2 0}$ & N/A \\
4 & $\mathbf{0 . 4 2}$ & $\mathbf{0 . 7 1}$ & -0.14 \\
5 & $\mathbf{1 . 0 9}$ & -1.06 & 0.98 \\
mCEI & $\mathbf{2 . 0 4}$ & $\mathbf{2 . 6 8}$ & $\mathbf{2 . 8 6}$ \\
dmCEI & $\mathbf{1 . 1 0}$ & $\mathbf{1 . 1 5}$ & $\mathbf{2 . 9 1}$ \\
\hline
\end{tabular}

by local effects (e.g., localized radiative cooling) compared to annual extreme temperature and daily extreme maximum temperatures. The greater influence of local effects leads to reduced spatial coherence, which may explain the weaker correlation. A strong level of agreement between the variations of mean and extreme temperature in Australia was also found by Alexander et al. (2007).

Table 2 shows the trends in the mCEI and dmCEI and their components from 1911 to 2008 and from 1957 to 2008. For the temperature-based components, increases (positive trends) represent tendencies toward more widespread hot extremes and decreases (negative trends) toward cold extremes. The increase in the extreme annual maximum temperature component of $2.57 \%$ decade $^{-1}$ (Table 2) stems from significant trends during autumn and winter that are greater than $1.97 \%$ decade $^{-1}$ (not shown). There was a significant increase in the annual minimum temperature component of $3.94 \%$ decade $^{-1}$, which is due to significant trends during summer, autumn, and spring of at least $3.10 \%$ decade $^{-1}$.

From 1911 to 2008, there were increases in the extent of extreme moisture surplus conditions. Such conditions were most apparent during the mid-1950s, early 1970s, and late 1990s (Fig. 3a), which coincide with periods of high annual-average Australian rainfall (Hennessy et al. 1999). These conditions were reflected in the extreme wet/dry days component (Fig. 3c) and the heavy rain day component (Fig. 3b) except during the mid-1950s, indicating that the greater expanse of extreme wet conditions during this time was not due to widespread heavy rain days. The annual variations in Australian mean rainfall and the drought/moisture surplus and wet/dry days components track closely, with correlations of 0.92 and 0.83 , respectively. However, the extent of heavy rain days is less dependent on mean rainfall and the two have a correlation of 0.42 , suggesting that Australian mean rainfall and the extent of heavy daily rainfall are not closely related.

The extent of annual positive (wetter) and negative (drier) extremes changed around 1973 (Fig. 3a). Prior to this time, a larger area of Australia had an anomalous extent of extreme dry conditions during $68 \%$ of years, whereas post -1973 this was true for only $31 \%$ of years. The trends from 1911 to 2008 confirmed this, with a significant increase in the annual extent of Australian extreme moisture surplus conditions of $2.20 \%$ decade $^{-1}$ (Table 2). The annual increase in extreme moisture surplus conditions was a culmination of similar trends during all seasons, all of which were significant except during winter. This increase was accompanied by significant increases in the heavy rain days component of $0.42 \%$ decade $^{-1}$ and the wet/dry days component of $1.09 \%$ decade $^{-1}$. Such trends indicate that, although there have been recent prolonged dry conditions in some parts of Australia (Hope et al. 2006; Murphy and Timbal 2008), the regions in which these signals have been detected are small and have not significantly expanded between 1911 and 2008. The increases toward more widespread heavy rain days and the extreme number of wet days mostly stemmed from significant increases during summer.

\section{b. Comparisons with high-quality datasets}

The $\mathrm{mCEI}$ and dmCEI components were recalculated from gridded observations from 1957 to 2008, and their interannual and 5-yr variations were compared to the high-quality station records over the same period. The probability that a missing data point is also an extreme value increases with more missing data. Therefore, a station was not used for a particular year if it contained more than $10 \%$ missing data. As such, during some years as few as 70 temperature stations and 80 rainfall stations were used to generate the Australian high-quality mCEI and dmCEI component time series.

The annual and seasonal correlations between the gridded and high-quality time series were greater than 0.90 for the majority of mCEI and dmCEI temperature components (Table 3). The associations were similar on 5-yr time scales. A weaker correlation of 0.81 for Australian daily minimum temperature extremes on 5-yr scales (Table 3) was due to inconsistencies between 1959 and 1970 (Fig. 2d). Similar, but smaller, inconsistencies were also apparent for daily maximum temperatures. To investigate further, monthly mean minimum and maximum temperatures were calculated from the daily temperature grids and compared to the monthly 
TABLE 3. The correlations and RMSE between the time series generated from the gridded and high-quality time series. The agreement on annual and 5-yr time scales is shown for the annual Australian mCEI, dmCEI, and their components.

\begin{tabular}{lcccc}
\hline \hline Component & $r_{\text {annual }}$ & $r_{5-\mathrm{yr}}$ & $\mathrm{RMSE}_{\text {annual }}(\%)$ & $\mathrm{RMSE}_{5-\mathrm{yr}}(\%)$ \\
\hline 1 & 0.98 & 0.98 & 4.59 & 2.64 \\
1 (daily) & 0.93 & 0.90 & 8.00 & 5.02 \\
2 & 0.98 & 0.98 & 4.95 & 2.27 \\
2 (daily) & 0.81 & 0.56 & 11.31 & 9.34 \\
4 & 0.34 & 0.42 & 5.84 & 2.80 \\
5 & 0.78 & 0.96 & 13.89 & 3.07 \\
mCEI & 0.94 & 0.98 & 4.58 & 1.38 \\
dmCEI & 0.90 & 0.89 & 5.53 & 2.79 \\
\hline
\end{tabular}

grids and to the high-quality station data. This revealed that the gridded daily temperatures showed "warmer" values prior to 1970, leading to similarly warmer dmCEI components 1 and 2 (Fig. 2). Though this has little to no effect on the interannual variations, there are implications for the trends of the dmCEI temperature-based components.

In all regions, the associations between the time series were weakest during summer and for the extreme daily minimum temperature component, where they were often less than 0.90 . The RMSE was mostly less than $10 \%$ and the reduced variance in the 5-yr smoothed time series decreased the RMSE further (Table 3). The RMSEs were the equivalent of approximately one-half a standard deviation for the temperature-based components. Given the spatial distribution of the high-quality temperature records (Fig. 1b), the close agreement between the two time series (Figs. 2 and 3) suggests that extreme temperatures have long spatial scales (on the order of hundreds of kilometers). However, the somewhat weaker correlations for the extreme daily minimum temperature component, combined with the smaller variations compared to extreme annual and seasonal temperatures, indicate that these events are more localized.

The similarities between the interannual and 5-yr variations in the gridded and high-quality temperature component time series meant the linear trends over the 1957-2008 period were also similar. However, the trends from the high-quality daily temperature components were stronger and more significant than from their gridded counterparts (Table 2). The weaker trends in daily temperature components calculated from the gridded data reflect the warmer-temperature bias previously discussed. The existence of this bias prior to approximately 1970 has lead to an underestimation of the trend in daily temperature extremes when calculated from the gridded dataset (Table 2).

Area-weighting reduces biases toward regions with higher station density. This suggests that the gridded data are underestimating the increase in the extent of hot temperature extremes, rather than the differences between the trends stemming from biases due to the locations of the high-quality station data, which are more heavily concentrated in the south and east. However, the differences in the trends were generally small and the similarities between the trends and variations of both time series confirm that the gridded data are accurate enough to faithfully represent the spatial extent of extreme temperatures from 1957 to 2008. For this reason there is confidence in the representation of the temperature-based components by the gridded data from 1911, as there were strong similarities between the time series even when as few as 70 stations were used for the high-quality components in the Australian region. This is a similar number of stations used to generate the gridded temperature surfaces at the beginning of the record (Fig. 1a). The uncertainty in the pre-1957 period is larger for daily minimum temperature extremes, which are more localized and harder to represent with sparse station data.

The representations of the heavy rain days component were usually quite different between the gridded and high-quality datasets, owing to the often spatially inconsistent nature of extreme daily rainfall events. The correlations between the Australian time series ranged between 0.14 (during summer) and 0.75 (during winter). The RMSEs were mostly less than $10 \%$, which represented between approximately one and two standard deviations. The trends calculated from both datasets were usually different in magnitude and often opposite in sign (Table 2) because of the large differences in the interannual variations between the time series. There was a marked improvement in the agreement between the time series with increased station density. Examining a subregion with higher station density illustrates the improved agreement between the datasets resulting from a denser network of high-quality stations. In the southeast, 85 stations generated the high-quality heavy rain days component time series (Fig. 5b). Here, the annual and seasonal interannual correlations were consistently greater than 0.63 , and 5 -yr correlations were as strong as 0.82 . The RMSEs were less than the equivalent of one standard deviation (approximately 5\%). However, the linear trends produced by each dataset continued to be different despite the improved agreement between variations of each time series, as they can be sensitive to highly variable data (Gallant et al. 2007). The stronger agreement between the variations of the two time series with higher station density indicates that the majority of the differences between the datasets has stemmed from a sparse high-quality data network for this region. However, it is also possible that errors exist 
in the gridded data due to the varying numbers of stations contributing to each grid box over time (Fig. 1a) and smoothing of extremes due to the contribution of multiple stations to each grid box. This might be particularly important in regions where convective events are responsible for the largest proportion of extreme daily rainfall, such as the tropics. Though a higher-density network of 85 stations in the southeast leads to better agreement with the gridded data, it is not necessarily applicable to all regions, particularly those where mesoscale rainfall activity significantly contributes to extreme daily rainfall (e.g., the northwest and northeast regions during summer). Given that 85 stations only can represent spatial variations in heavy rain days in the southeast, it is likely that the national grid, generated from between 2967 and 7278 stations, will be representative of spatial variations in Australian heavy rain days, assuming that the data are accurate. However, this cannot be confirmed without comparison with a spatially dense high-quality daily rainfall dataset.

The interannual and 5-yr variations of the gridded and high-quality time series of the wet/dry days component followed closely in all regions, demonstrating that the component has strong spatial coherence (Fig. 3c). All Australian and subregional interannual correlations were larger than 0.71 , except during spring in the northwest and Australian regions where the correlations were 0.42 and 0.63 , respectively. The relationships improved substantially for the 5-yr variations and the correlations often exceeded 0.90 (Table 3), implying that the gridded data represents the lower-frequency variations of the component well; the greater the density of the highquality stations, the stronger the relationship between the datasets. The RMSE generally remained below $15 \%$ (mostly less than one standard deviation of the component variations), and like the correlations, the RMSE was substantially reduced for lower-frequency variations (Table 3). The linear trends of both datasets were mostly consistent in magnitude and significance. However, in some cases, a single, large outlier caused a trend that was opposite in sign (Fig. $3 \mathrm{c}$ and Table 2). The strong similarities between the datasets suggest that the gridded data accurately represents spatial variations in this component.

\section{c. The Australian $m C E I$ and $d m C E I$}

The mCEI and dmCEI components were combined to show variations in the anomalous spatial extent of Australian climate extremes from 1911 to 2008. Figure 4 shows the annual Australian time series with negative values indicating the fraction of the country experiencing extreme cold and dry conditions and positive values indicating extreme hot and wet conditions. Measured from 1911 to 2008, the annual Australian mCEI and dmCEI time series had average deviations from zero of $10 \%$ and $9 \%$, respectively. Figure 4 a shows that the 5-yr anomalies of the Australian annual mCEI predominantly changed in sign during 1971 and during 1985 for the dmCEI. Prior to these times, large proportions of the Australian landmass experienced extreme cold and dry conditions during $78 \%$ and $62 \%$ of years for the mCEI and dmCEI, respectively. However, after these times, $18 \%$ and $25 \%$ of years only had such conditions. Of the 14 years from 1995 to 2008, only 1 (2) year produced negative anomalies in the mCEI (dmCEI). The prevalence of the recent positive anomalies is strongest in the mCEI, where the median anomaly in the annual values since 1995 has been larger than one standard deviation above normal (approximately 12\%).

The tendencies described above were reflected in the linear trends in the Australian mCEI that were significant at the $1 \%$ level during all seasons, and trends in the Australian dmCEI that were significant at the 3\% level during all seasons except winter. The weaker trends in the gridded dmCEI reflect the warm bias in the gridded daily temperature data prior to 1970 . The annual trends in the mCEI and dmCEI from 1911 to 2008 were 2.04\% and $1.10 \%$ decade $^{-1}$ respectively. The trends from 1957 to 2008 were of a similar magnitude when calculated using the gridded dataset. However, the trends calculated from the high-quality stations were larger, particularly for the dmCEI, where the 1957-2008 trend was more than twice the size of that calculated from 1911 to 2008 (Table 2). The weaker trend in the dmCEI calculated from the gridded data is further evidence of the warm bias in the daily gridded temperature data prior to 1970 . Seasonally, the trends were strongest during summer and weakest during winter. The tendencies in the mCEI and dmCEI represent an increasing proportion of Australia experiencing hot and wet extremes between 1911 and 2008 that were primarily due to changes during summer and spring.

\section{d. Regional changes in the $m C E I, d m C E I$, and their components}

Significant trends in regional Australian climate extremes have been identified (Alexander et al. 2007; Gallant et al. 2007). During the twentieth and early twenty-first centuries, decreasing trends in heavy rain days have been observed in areas within the southeast and southwest regions defined here (Gallant et al. 2007) and increases have been observed in the northwest (Alexander et al. 2007). Extreme high temperatures have increased across most of the continent from the middle of the twentieth century with the exception of some small areas in northwest Australia and some coastal 
sections of southwest Australia (Alexander et al. 2007). The regional differences prompt an examination of regional changes in the mCEI, dmCEI, and their components for the four subregions shown in Fig. 1.

All regional trends in the annual minimum temperature component of the mCEI were significant, with the largest trends of $5.52 \%$ and $5.32 \%$ decade $^{-1}$ occurring in northeast and southwest Australia, respectively. Extreme maximum temperature trends were weaker, but still significant in all regions, ranging between $2.13 \%$ and $2.83 \%$ decade $^{-1}$. There was a significant negative trend in the extent of extreme daily minimum temperatures in the northwest region during winter, implying increases in the extent of cold daily minimum temperature extremes by $1.22 \%$ decade $^{-1}$ in the region. Alexander et al. (2007) also detected increases in the cold extremes of minimum temperatures in this region between 1957 and 2005. The regional trends in the extent of extreme temperatures are consistent with previous studies that have demonstrated increases in the occurrence and severity of extreme minimum and maximum temperature events across most of Australia since the middle of the twentieth century (Collins et al. 2000; Alexander et al. 2007). The results here show that such trends have existed since 1911.

The increase in the area of Australia experiencing extreme wet and moisture surplus conditions has mostly stemmed from the expansion of these conditions in the northwest, where there were significant trends in all annual moisture-based components. The increases in annual soil moisture and wet/dry days components were $3.90 \%$ and $3.25 \%$ decade $^{-1}$, respectively, and there was an increase of $0.61 \%$ decade $^{-1}$ in the extent of heavy rain days. These trends were due to significant increases of a similar magnitude during summer. There was little evidence of increasing widespread extreme dry conditions except in the southeast during all seasons and during winter only in the southwest. However, these are two of the most densely populated regions in Australia where the socioeconomic impacts have the potential to be the greatest. Therefore, the trends in these regions are discussed in further detail.

In the southeast, the annual and seasonal long-term trends indicated more widespread extreme dry days in the region from 1911 to 2008 of between $0.16 \%$ (during summer) and $1.15 \%$ decade $^{-1}$ (during winter), though none of these trends were significant. The areal extent of heavy rain days has decreased in the southeast during autumn since the early 1990s (Fig. 5b), which was not reflected in the long-term trend of this component. This persistent anomaly is consistent with reported reductions in mean and extreme daily rainfall during autumn at locations across the southeast since the end of the twentieth century (Alexander et al. 2007; Gallant et al. 2007). The increase in the extent of extreme dry days in the southeast since the mid-1990s (Fig. 5c) is more apparent than changes to drought and heavy rain day conditions (Fig. 5). Since 1993, 14 of 16 years have experienced abnormally large areas with an extreme proportion of dry days. However, only 8 and 10 years (of 16) experienced contracted areas of heavy rain days and more widespread drought conditions respectively. The magnitude of the median anomaly of drought extent (11\%) was almost 4 times larger than median extreme moisture surplus anomalies (3\%) between 1993 and 2008. From this evidence, it appears that the extreme dry conditions post-1993 during autumn in the southeast stem from a greater expanse of extreme dry days combined with a larger extent of drought and a smaller extent of extreme moisture surplus conditions when such conditions occur.

There was an increase in the area of the southwest experiencing extreme dry days during winter only. While the increasing trend is consistent with reported declines in mean and extreme winter rainfall in the far southwest of the southwest region since the mid-1970s (Alexander et al. 2007; Gallant et al. 2007), a persistent negative anomaly in the areal extent of dry conditions did not appear in the southwest during winter until the late 1990s (Fig. 6). This indicates that the extreme dry conditions from the 1970s were confined to a small area, which has only recently begun to expand since the late 1990s.

To examine the trends in concurrent drying and warming of the southwest and southeast, the mCEI and dmCEI were recombined to show variations in the areal extent between cold and wet or hot and dry extremes. The rainfall- and soil moisture-based components (3-5) were regenerated by subtracting the wet from the dry tails (Table 1 describes the subtraction of dry from wet tails for components 3-5), and the mCEI and dmCEI were recalculated using these results. For the mCEI, there were significant positive trends in the southeast and southwest regions from 1911 to 2008 of $1.08 \%$ and $1.36 \%$ decade $^{-1}$ respectively, during winter, indicating a move to a greater extent of extreme hot and dry conditions. From 1957 to 2008, these trends were stronger and more significant and were $2.31 \%$ and $2.82 \%$ decade $^{-1}$ for the southeast and southwest, respectively. During autumn in the southeast, the mCEI shows a larger extent of extreme hot and dry conditions, with a significant increase of $1.29 \%$ decade $^{-1}$ from 1911 to 2008 and $2.96 \%$ decade $^{-1}$ from 1957 to 2008 . The trends in the dmCEI for both regions during winter and during autumn in the southeast ranged from $0.33 \%$ to $1.50 \%$ decade $^{-1}$. However, none were significant. 

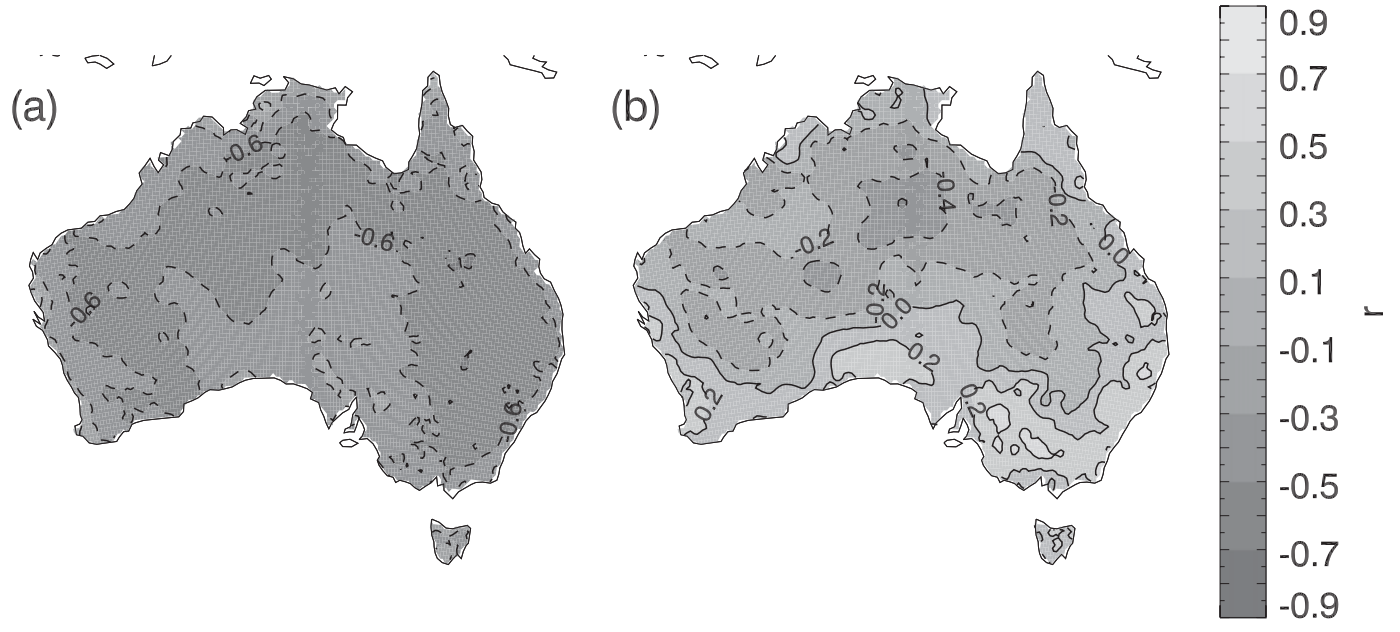

FIG. 7. The interannual correlations between detrended, annual (a) maximum temperature and rainfall anomalies and (b) minimum temperature and rainfall anomalies. Dashed contour lines indicate negative correlations and solid contour lines positive correlations.

\section{Discussion}

There are strong and significant relationships between interannual variations of Australian temperature and rainfall (Fig. 7). Establishing the associations between the temperature and rainfall/soil moisture-based components of the mCEI and dmCEI identifies any similar relationships between the spatial extents of extremes of these variables. Any interdependence between the extreme temperature and rainfall components is further justification for examining them simultaneously via the mCEI and dmCEI and provides an impetus for future work that examines the physical processes behind such relationships.

Detrended rainfall- and soil moisture-based components were compared to the temperature-based components. The strongest interannual and 5-yr associations were between the maximum temperature components and the drought/ moisture surplus and wet/dry days components. For the Australian region, the annual correlations ranged between -0.57 and -0.70 , which is comparable to the correlation between Australia-averaged annual mean maximum temperature and rainfall from 1911 to 2008 of -0.68 . The associations between these components were strongest during spring, suggesting an association with the El Niño-Southern Oscillation, which influences mean Australian rainfall and maximum temperatures at this time (Allan et al. 1996). The correlations between the heavy rain days and extreme maximum temperature components were weak and rarely significant, demonstrating that the variations in the areal extent of heavy rain days do not accompany similar variations in extreme maximum temperatures.

In northern Australia, the sign of the relationships between the extent of extreme minimum temperatures and rainfall-/soil moisture-based components were the opposite to those of the mean variations (Fig. 7b). However, most of the correlations were less than 0.35 and were often insignificant. When significant correlations did exist, they implied that when there was an expansion of extreme hot minimum temperatures, there was also an expansion of wetter extremes. Conversely, an expansion of extreme cold minimum temperatures was associated with expanded dry extremes. The only negative association (i.e., coupled colder and wetter extremes) was in the southwest during spring. The strongest correlations were in the southeast during autumn and winter, where the correlations were larger than 0.5 . Physically, the positive association can be explained through the process of increased radiative cooling at night, with dry conditions due to a lack of clouds and moisture in the atmosphere.

The strongest associations between the Australian and subregional mCEI and dmCEI temperature and rainfall/soil moisture components described a positive relationship between the extent of extreme hot maximum temperatures and dry conditions, and vice versa, on interannual and 5-yr time scales. However, such a relationship conflicts with the longer-term (1911-2008 and 1957-2008) tendencies for each of these components, where there have mostly been significant trends toward a greater extent of combined hotter and wetter extremes. As such, the physical processes that govern the interannual and 5-yr associations are unlikely to be responsible for the long-term changes. Though the direction of the long-term tendencies and interannual and 5 -yr associations between extreme minimum temperatures and precipitation/soil moisture conditions are consistent, it is difficult to argue that any causal factor is the same, as 
the associations on interannual and 5-yr time scales were mostly weak and statistically insignificant.

\section{Conclusions}

The mCEI and dmCEI provide a simple way of examining concurrent changes in the spatial extent of Australian temperature, rainfall, and soil moisture extremes. Variations and trends in daily temperature extremes prior to 1957 were presented for the first time, and there is confidence in the accuracy of the changes described from 1911 to 2008. The unified climate extremes indices have provided a broad-scale picture of changes in a range of Australian extremes throughout the twentieth and early twenty-first century that are useful for communication with nonscientists. Around the mid-late 1970s, the broad-scale Australian environment changed from a period where colder and drier extremes dominated to one where hotter and wetter extremes were more prevalent. Such changes manifested in annual, seasonal, and daily extremes. There was some evidence of increases in the prevalence of hot and dry extremes in southern and eastern parts of Australia during winter, particularly since the mid-1990s. There were significant relationships between the extent of maximum temperature and rainfall extremes on interannual and 5-yr time scales. However, the direction of the long-term trends was the opposite to that expected given such relationships, indicating that the processes governing each may be quite different.

Acknowledgments. This research was supported by the Australian Research Council through the Discovery Projects funding scheme (Project FF0668679).

\section{REFERENCES}

Alexander, L. V., and Coauthors, 2006: Global observed changes in daily climate extremes of temperature and precipitation. J. Geophys. Res., 111, D05109, doi:10.1029/2005JD006290.

—, P. Hope, D. A. Collins, B. Trewin, A. H. Lynch, and N. Nicholls, 2007: Trends in Australia's climate means and extremes: A global context. Aust. Meteor. Mag., 56, 1-18.

Allan, R., J. Lindsay, and D. Parker, 1996: El Niño Southern Oscillation and Climate Variability. CSIRO, $405 \mathrm{pp}$.

Burkholder, B., 2007: An assessment of United States climate variations using the Climate Extremes Index. M.S. thesis, University of Oklahoma, $103 \mathrm{pp}$.

Collins, D., P. Della-Marta, N. Plummer, and B. Trewin, 2000: Trends in annual frequencies of extreme temperature events in Australia. Aust. Meteor. Mag., 49, 277-292.

Della-Marta, P., D. Collins, and K. Braganza, 2004: Updating Australia's high-quality annual temperature dataset. Aust Meteor. Mag., 53, 75-93.

Easterling, D. R., J. L. Evans, P. Y. Groisman, T. R. Karl, K. E. Kunkel, and P. Ambenje, 2000: Observed variability and trends in extreme climate events: A brief review. Bull. Amer. Meteor. Soc., 81, 417-425.
Fouillet, A., and Coauthors, 2006: Excess mortality related to the August 2003 heat wave in France. Int. Arch. Occup. Environ. Health, 80, 16-24.

Frich, P., L. V. Alexander, P. Della-Marta, B. Gleason, M. Haylock, A. M. G. Klein Tank, and T. Peterson, 2002: Observed coherent changes in climatic extremes during the second half of the twentieth century. Climate Res., 19, 193-212.

Gallant, A. J. E., K. J. Hennessy, and J. S. Risbey, 2007: Trends in rainfall indices for six Australian regions: 1910-2005. Aust. Meteor. Mag., 56, 223-239.

Gleason, K. L., J. H. Lawrimore, D. H. Levinson, T. R. Karl, and D. J. Karoly, 2008: A revised U.S. climate extremes index. J. Climate, 21, 2124-2137.

Haylock, M., and Coauthors, 2006: Trends in total and extreme South American rainfall in 1960-2000 and links with sea surface temperature. J. Climate, 19, 1490-1512.

Hennessy, K. J., R. Suppiah, and C. M. Page, 1999: Australian rainfall changes, 1910-1995. Aust. Meteor. Mag., 48, 1-13.

Hope, P., W. Drosdowsky, and N. Nicholls, 2006: Shifts in the synoptic systems influencing southwest Western Australia. Climate Dyn., 26, 751-764.

Jones, D. A., W. Wang, and R. Fawcett, 2007: Climate data for the Australian Water Availability Project. Australian Bureau of Meteorology, $37 \mathrm{pp}$.

Karl, T. R., R. W. Knight, D. R. Easterling, and R. G. Quayle, 1996: Indices of climate change for the United States. Bull. Amer. Meteor. Soc., 77, 279-292.

Klein Tank, A. M. G., and G. P. Können, 2003: Trends in indices of daily temperature and precipitation extremes in Europe, 1946-1999. J. Climate, 16, 3665-3680.

Lavery, B., A. Kariko, and N. Nicholls, 1992: A historical rainfall dataset for Australia. Aust. Meteor. Mag., 40, 33-39.

Manton, M. J., and Coauthors, 2001: Trends in extreme daily rainfall and temperature in southeast Asia and the South Pacific: 1961-1998. Int. J. Climatol., 21, 269-284.

Murphy, B. F., and B. Timbal, 2008: A review of recent climate variability and climate change in southeastern Australia. Int. J. Climatol., 28, 859-879.

Plummer, N., and Coauthors, 1999: Changes in climate extremes over the Australian region and New Zealand during the twentieth century. Climatic Change, 42, 183-202.

Raupach, M. R., P. R. Briggs, V. Haverd, E. A. King, M. Paget, and C. M. Trudinger, 2009: Australian Water Availability Project: CSIRO Marine and Atmospheric Research component: Final report for phase 3. CAWCR Tech. Rep. 013, 72 pp.

Thiessen, A. H., 1911: Precipitation averages for large areas. Mon. Wea. Rev., 39, 1082-1084.

Trewin, B., 2001: Extreme Temperature Events in Australia. University of Melbourne, $239 \mathrm{pp}$.

Vincent, L. A., and E. Mekis, 2006: Changes in daily and extreme temperature and precipitation indices for Canada over the twentieth century. Atmos.-Ocean, 44, 177-193.

— , and Coauthors, 2005: Observed trends in indices of daily temperature extremes in South America 1960-2000. J. Climate, 18, 5011-5023.

You, Q. L., S. C. Kang, E. Aguilar, and Y. P. Yan, 2008: Changes in daily climate extremes in the eastern and central Tibetan Plateau during 1961-2005. J. Geophys. Res., 113, D07101, doi:10.1029/2007JD009389.

Zhai, P., X. Zhang, H. Wan, and X. Pan, 2005: Trends in total precipitation and frequency of daily precipitation extremes over China. J. Climate, 18, 1096-1108. 


\section{University Library}

\section{- M M I N E R VA A gateway to Melbourne's research publications}

Minerva Access is the Institutional Repository of The University of Melbourne

Author/s:

Gallant, Ailie J. E.;Karoly, David J.

Title:

A combined climate extremes index for the Australian Region

Date:

2010

Citation:

Gallant, Ailie J. E., \& Karoly, David J. (2010). A combined climate extremes index for the Australian Region. Journal of Climate, 23, 6153-6165, doi: 10.1175/2010JCLI3791.1.

Publication Status:

Published

Persistent Link:

http://hdl.handle.net/11343/32784 